\title{
Cervical Necrotizing Fasciitis-Case Report
}

\author{
*Cristina Otilia Laza and Altai Gelal \\ Department of ENT, University Ovidius, Europe
}

Submission: October 10, 2016; Published: October 19 , 2016

*Corresponding author: Cristina Otilia Laza, Department of ENT, ENT /OMF Clinic, Scju, Constanta, University Ovidius, Constanta -B-Dul Tomis 145, Europe.

\begin{abstract}
Necrotizing fasciitis is an unusual rare, progressive and life-threatening bacterial infection which spreads with frightening speed along the fascial planes and subcutaneous tissue resulting in extensive necrosis and often death. Rapidly spreading necrosis often causes systemic sepsis, toxic shock syndrome and multi organ failure. Necrotizing fasciitis of the neck is rare and commonly has a dental or pharyngeal origin. Factors affecting the success of the treatment of necrotizing fasciitis are early diagnosis, appropriate antibiotics and surgical debridement. In this article is presented a 65 years old homeless patient with necrotizing fasciitis of the neck and thorax, trigger point being an old neglected trauma with infection. Clinical features, pathogenesis and treatment of the case are discussed in the article. Rapid recovery required adequate medical treatment etiologic, also symptomatic and supportive, surgical with debridement with excision of the necrotic tissue, irrigations with antiseptics; local antibiotics early sterilization allowed adequate skin grafting with good results.
\end{abstract}

Keywords: Neck Fascias; Necrotizing Fasciitis; Soft tissue Infection; Surgical Debridement; Flesh Eating Disease

\section{Introduction}

Cervical necrotizing fasciitis is a fulminate infection, with necrosis of the connective tissue that spreads with high speed along the fascial planes. It was first described by Claude Pouteau în 1783 but clinically was defined by Joseph Jones in 1871, during the U. S. Civil War, first being described in military hospitals as gangrene. In 1918, Pfanner diagnosed as necrotising erysipelas" a patient with a beta haemolytic Streptococcus infection [14]. Wilson introduced the term necrotizing fasciitis (NF) in 1952. In general, the isease is more common in extremities, the genital region, and the abdomen, rare in head and neck. $1-10 \%$ and is limited only at the skin and subcutaneous tissue, muscle involvement is rare. Cervical type of such an infection is infrequent and its development is determined by the complexity of anatomical planes of the neck and continuity of the fascial planes with adjacent anatomical regions, notably thorax and mediastinum [5]. Idiopathic cases are not rare as aggressive broad spectrum antibiotic therapy may mask the primary site.

The fact that necrotizing fasciitis causes tissue necrosis and spreads rapidly along the fascial planes is due to the synergistic effect of enzymes meiped by the bacteria. The causative organism may be a single agent, commonly Group A beta haemolytic Streptococci or Staphylococccus Aureus or may be a polymicrobial infections. Polymicrobial infections are caused by mixed aerobic and anaerobic pathogens. Synergy between them contributes to the pathogenesis of polymicrobial fasciitis i.e. synergistic gangrene. Necrotizing fasciitis can be divided into 5 types [6-9]:

a) Necrotizing fasciitis Type I: Polymicrobial, is caused by non Group A streptococci and anaerobes and/or facultative anaerobes. Usually seen after trauma or surgery. There is involvement of subcutaneous fat and fascia with sparing of muscle and gas formation.

b) Necrotizing fasciitis Type II: Group A streptococcal is caused by Streptococcus pyogenes alone or associated with Staphylococcus aureus. With Streptococcal toxic shock syndrome. Predisposing factors are trauma, surgery or varicella infections.

c) Type III Clostridial myonecrosis: Gas fasciitis of the scrotum

d) Type $\mathrm{V}$ Lemierre's syndrome (A. Lemierre, 1936): Gangrene is characterized by its fulminate onset. The predominant features are muscle necrosis and gas production. The commonest causative organism is Clostridium perfrigens.

e) Type IV Fournier's gangrene (J.A. Fournier, 1883): necrotising Oropharyngeal infection with secondary thrombophlebitis of the Internal Jugular Vein and frequent metastatic infections. Caused by Fusobacterium necrophorium. In most cases, the pathogenic germs entry 
through a disruption of the skin caused by trauma or surgery

\section{Pathogenesis}

Of type I is not yet clarified possible there is a synergy between the germs in affecting human tissues, but for sure immune status of the host is so damaged than infection can spread very fast Being so rare there are just a few studies on the pathogenesis of necrotizing fasciitis. It describes a progressive liquefaction of fat and subcutaneous connective tissue underneath the skin of relatively normal appearance. Fascial planes decays, it produces necrosis and release of a fat tisular liquid [9]. Veins placed in liquefied subdermal plane begin thrombosis and the skin becomes congested at first and then marbled. Subsequently arterial circulation is affected and the skin becomes pale, leading to gangrene. The response is characterized by an intense polymorphonuclear infiltration focal necrosis and formation of micro-abscesses. Rapid disease progression is another distinctive element of necrotizing fasciitis if the characteristic clinical signs are present, the clinical diagnosis does not require confirmations-or bacteriological examination [10].

The treatment is somewhat similar to extensive burns. The practice; repeated lavages debridement of the wound -dressings made preferably in operation room. Favourable evolution gradually appears in the depth of the wound granulation tissue and the skin is attached to this granulation tissue, from the edges of the wound. Antibiotic therapy can be guided by microbial culture; hyperbaric therapy (where technical conditions permit) can be applied, although no studies to prove its effectiveness.

Despite effective surgical and medical treatment, the prognosis remains reserved with increased mortality. Mortality may be due to general issues of major bleeding from about 10 days after surgery, when the infection appeared to be solved. The main reasons for the disease are odontogenic infections, bad oral hygiene, cavities or dental treatment. In $2 / 3$ of cases can fallow a skin trauma or maxillo-facial surgeries. The disease frequently develops in individuals that have an insufficient and low immune system, diabetes mellitus commonly seen in middle aged individuals.

\section{Case Presentation}

Patient M.M, 65 years old, was referred to our emergency department, being picked from the streets by a SMURD Unit. Our patient without family, income leaved on the streets and was sleeping in a sour channel. He was admitted with high fever, bad general status, dysphagia, odinophagia, excruciating pain in the left side of the neck and periauricular. He described a temporal trauma 2 weeks before arrival in our department, with a small wound in the retro auricular left area, but he neglect this trauma till the 3rd week, when the lesion become red, with extension on the latero-cervical area [11-15]. Pain became more severe day by day, and his general status deteriorates so he fall on the street were was discovered by the paramedics .

\section{General examination}

On presentation we discover a patient in a very bad status , with high fever, severe asthenia, very thin, very dirty, lice infested, obnubilated, late reactions, responding with difficulty to the questions. He had major pain in the cervical area, subcutaneous oedema and a skin defect on retroauricular left area, extended laterocervical.

\section{Cervico-facial examination}

The wound appeared necrotic with a dark base and a lots of fistulous tracts with a foul, aerated, frothy discharge [16]. Skin over the latero -cervical area and right thoracic wall appeared purple discoloured, with marked oedema. Palpation revealed a painful, infiltrated, friable area with gaseous crepitating. At the beginning my first impression was of an Actinomycosis, maybe a lymph nodes tuberculosis- scrofulosis so I take multiple samples from the pus and tissue and order to the laboratory direct examination, specific coloration-ex. Zielh-Nielsen or acid, fast bacilli like Mycoplasma pneumoniae, for aerobic anaerobic bacterias but also mycological examination with sensibility to antibiotics, antifungal drugs. But when next day I remove the dressing I was stunned by the massive extension of the lesions on the neck and thorax so fast I ask at the lab about the results and they confirm my suspicion of flesh eating disease. Examination of the mouth was difficult to perform because of the pain, revealed poor oral hygiene, multiple residues, cavities, bad breath fetid [17] (Figure 1).

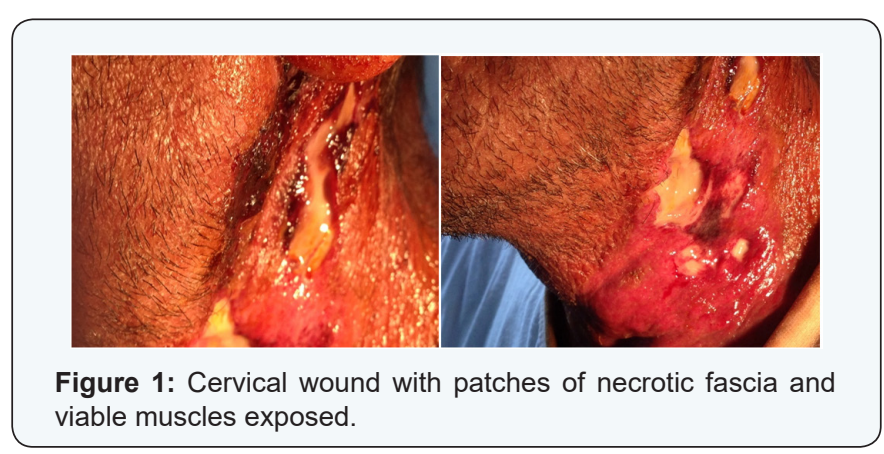

Imagistic: X-ray of the lungs-traces of Tuberculosis. CTneck-thorax-superficial inflammation, necrosis, gas formation, no extension deep or in mediastinum.
A. Laboratory Tests
i. Blood count anemia, leukocytosis,
ii. Coagulation TQ: 15.4 (12-15 / sec), INR: 1.24 (1.00- 1.20), APTT: 22.6 (24.3 to $35.0 / \mathrm{sec}$ ).

iii. Creatinine 1.5 (0.5 to 1.3 / mg / dl) Urea: 99 (15-45 / $\mathrm{mg} / \mathrm{dl}$ )

iv. Total protein: 6.4 (6.4 to $8.2 / \mathrm{g} / \mathrm{dl})$

v. Glucose: 157 (60-115 / mg / dL ), slight transient 


\section{Global Journal of Otolaryngology}

increase was not considered significant and subsequent values returned to normal

vi. Potassium: 3.2 (3.8 to 5.2 / mmol / l) Sodium 147 (138155 / mmol / l),

vii. ALT: 90 (5-65 / U / L) AST: 97 (2-40 / U / L)

viii. Test HIV negative, HBS Ab, Ac HBC neg, Quantiferon test negative

ix. Bacterial cultures from the wound showed a mixed flora with Streptococcus pyogenes and Staphylococcus aureus could be isolated and tested for antibiotic sensibility [18].

Pathological examination confirmed inflammation with tendency to abscess formation that extended between viable muscular fibres. Fat tissue shows massive lyponecrosis with recent thrombosis of small vessels associated to inflammatory infiltration (Figure 2).

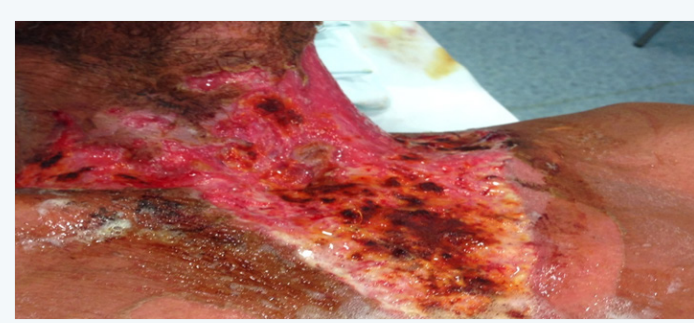

Figure 2: Extension of the necrosis in the cervical and thoracic areas.

\section{Treatment}

In emergency we start the treatment.

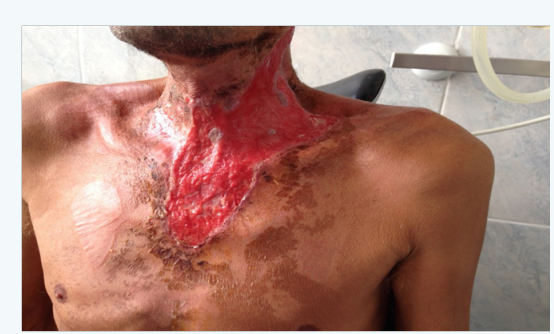

Figure 3: Final aspect of the area, granulated, no infection, prepared for grafting.

a. In ICU medical treatment with sustaining of the vital functions, antialgics, hydratation, sustaining the general status with parenteral nutrition-glucoses, amino-acids, lipids, vitamins electrolytes nutrition solutions -in OR under general anaesthesia we perform wound toilet, washing with betadine, oxygenated water, and continue with soft tissue debridement and resection of necrotic areas, wet dressings soaked in betadine and antibiotic solutions, topical application of boric acid powder iodated, hampicin, neomycin, bacitracin. This toilet was performed every day with repeated wash outs with antiseptic solutions, sometimes debridement and skin excision. The evolution of the process was positive -we succeed to stop the progression of necrosis and heal the infection, day by day general condition improves and basis of the wound began granulation course, small islands of epithelium appear from the edges till grafting was possible [19] (Figure 3).

Patient was referred to the plastic surgery Clinic was the skin defect was covered. All skin grafts survived and patient had a swift recovery being discharged after an additional postoperative week. Early postoperative functional results are very good with no limitations in movements, while cosmetic aspects are acceptable. A psychiatric examination revealed a Dementia probably alcohol induced -we insist on this because our patient was completely amnesic, could not remember his name, or were his house, wife or children [20]. We contact the police and social department but were impossible to discover a relative, so, when we discharge the patient completed healed social worker assistant help him to obtain a place in a social shelter also recuperate his ID, retirement pension. He is still coming every month to check -up and is in good health.

\section{Discussion}

Cervical necrotizing fasciitis is an infection that rapidly progresses on the fascial planes, even if cases are rare. It comprises $2.6 \%$ of all head and neck infections. It is more common in middle aged males. The cause it is the most frequently dental pathology, followed by parapharyngeal and peritonsillar infections. Surgeries and traumatic lacerations may be considered possible causes. Necrotizing fasciitis is an insidiously advancing soft tissue infection characterized by widespread fascial necrosis. Organisms spread from the subcutaneous tissue along the superficial and deep fascial planes, presumably facilitated by bacterial enzymes and toxins. This deep infection causes vascular occlusion, ischemia, and tissue necrosis. In most cases aetiology is plurimycrobial.

(Type I necrotizing fasciitis) and this form may initially be mistaken for wound cellulites more so when toxicity is not obvious. Type II is a streptococcal infection also called "flesh eating infection" and type III is a gas gangrene with myonecrosis. The case presented in this paper was a typical type II infection with infection spreading on fascial planes and association with vascular thrombosis a super infection after an initial traumatic wound. The disease starts suddenly and violently with a high temperature. The infection causes necrosis in subcutaneous tissue as a result of intense lymphocytic infiltration, vascular thrombosis, and oedema as it spreads [20]. The disease progresses more rapidly in patients with diabetes, chronic kidney failure, insufficient immune systems, or have undergone surgery, trauma, and radiotherapy previously. Our patient was a chronic 
alcoholic men living in poor conditions; with malnutrition, toxic hepatophaty, also sign of dementia.

Suitable radiological examinations should be requested as soon as possible in order to determine the extent of the disease, and to correctly evaluate the airway of the patient. The CT enables us to see the formation of subcutaneous gas and abscess. Even though the CT image does not illustrate significant pathology, it helps guide surgical intervention. Hyperbaric oxygen and intravenous immune globulin treatment decreases the mortality rate. The key in management is early recognition and early debridement. Of course resuscitation is to be started immediately and empirical antibiotics commenced even before the first surgical gesture, with later tailoring according to in vitro testing's.

Aggressive surgery implies to remove all non-viable tissue, without concern for further reconstruction preserving nonviable structures for a future cosmetic result is responsible for continuous toxicity and infection progression beyond the healthy margins. Repeated debridements are required as lesion may progress away from apparent viable limits of resection. Bleeding can be a problem mostly if associated with intravascular coagulation, but in most cases bleeding from small vessels is a sign of adequate resection. Complex anatomy of the neck allows progression along superficial as well as deep fascial structures $[8,20]$. Continuity of the neck fascia with mediastinum and thoracic wall structures favors progression towards these anatomic areas. Appropriate surgical management of deep neck infections is predicated on a comprehensive understanding of the anatomy of the head and neck.

All infected spaces should be readily opened and drained. One should take into account possible spreading to these spaces and the pictures we present clearly demonstrate the importance of adequately debridement fascia in these spaces. Reconstruction should be decided together by ENT surgeon in charge and the plastic surgeon but early grafting should be delayed until bacteriological eradication. A good level of trust and communication between the two specialties will speed up the procedure. Mortality in cervico-facial fasciitis is almost $40 \%$.

\section{Complications}

a. Superficial nerves are damaged, producing the characteristic localized anaesthesia.

b. Septicemia ensues with systemic toxicity.

c. Haemorrhage cause by erosion of a large vessels
d. Aesthetics- mutilation
e. Mediastinitis

\section{Conclusion}

Necrotizing fasciitis is rarely seen in the head and neck region, but the clinician must be aware that the illness may occur and capable to applied a good clinical examination, a make a correct empiric antibiotic selection, and an appropriate surgical intervention. The management of necrotizing fasciitis affecting cervical spaces continues to be a challenge and require surgical skills and courage to insure an early aggressive debridement. Rapid and suitable medical and surgical treatment, applied before the disease spreads, and before mortality-increasing complications arise, increases the rate of success.

\section{References}

1. Meleney FL (1929) Hemolytic Streptococcus Gangrene: Importance of early diagnosis and early operation. J Am Med Assoc 92: 2009-2012.

2. Howard J Beck, John R Salassa, Thomas V Mccaffrey, Paul E Hermans (1984) Life-threatening soft-tissue infections of the neck. Laryngoscope 94(3): 354-362.

3. Krespi YP, Lawson W, Blaugrund SM, Biller HF (1981) Massive necrotizing infection of the neck. Head Neck Surg 3(6): 475-481.

4. Morrow JS, Gianoli GJ (1993) Cranio-cervical necrotizing fasciitis. J La State Med Soc 145(7): 297-300.

5. Helmy AS, Salah MA, Nawara HA (1997) Life-threatening cervical necrotizing fasciitis. J R Coll Surg Edinb 42: 410-413.

6. Díaz Manzano JA, Cegarra Navarro MF, Medina Banegas A, López Meseguer E (2006) Diagnostico y tratamiento de la fascitis necrotizante cervical. Evolucion tras una angina de Ludwig. An Otorrinolaringol Ibero Am 33(3): 317-322.

7. Robert A Schwartz, Dirk M Elston (2009) Necrotizing fasciitis. E-Medicine.

8. Hasham S (2005) Necrotizing fasciitis - Clinical review. BMJ 330(7495): 830-833.

9. Asad Islam, Michael Oko (2008) Cervical necrotising fasciitis and descending mediastinitis secondary to unilateral tonsillitis: a case report. Journal of Medical Case Reports 2: 368.

10. Miles BA, Myers L (2009) Management of Deep Space Cervical Infection. The University of Texas South western, Medical Center at Dallas, USA.

11. Lorenzini G, Picciotti M, Di Vece L, Pepponi E, Brindisi L, et al. (2011) Cervical necrotizing fasciitis of odontogenic origin involving the temporal region-a case report. J Craniomaxillofac Surg 39(8): 570-573.

12.Zhang WJ, Cai XY, Yang C, Zhou LN, Cai M, et al. (2010) Cervical necrotizing fasciitis due to methicillin-resistant Staphylococcus aureus: a case report. Int J Oral Maxillofac Surg 39(8): 830-834.

13. Giovanna Bono, Antonina Argo, Stefania Zerbo, Valentina Triolo, Paolo Procaccianti (2008) Cervical necrotizing fasciitis and descending necrotizing mediastinitis in a patient affected by neglected peritonsillar abscess: a case of medical negligence. Journal of Forensic and Legal Medicine 15(6): 391-394.

14. Feinerman IL, Tan HK, Roberson DW, Malley R, Kenna MA (1999) Necrotizing fasciitis of the pharynx following adenotonsillectomy. Int J Pediatr Otorhinolaryngol 48(1): 1-7.

15. Hohlweg-Majert B, Weyer N, Metzger MC, Schön R (2006) Cervicofacial necrotizing fasciitis. Diabetes Res Clin Pract 72(2): 206-208. 
16. Bilbault P, Castelain V (2008) Life-threatening cervical necrotizing fasciitis after a common dental extraction. Am J Emerg Med 26(8): 971-977.

17. Johnny C Mao, Michael A Carron, Kimberly R Fountain, Robert Stachler, George H Yoo, et al. (2009) Craniocervical necrotizing fasciitis with and without thoracic extension: management strategies and outcome. American Journal of Otolaryngology 30(1): 17-23.

18. Delaney P, Rafiq R, Dodd M (2010) Craniocervical necrotising fasciitisan interesting case with review of the literature. Br J Oral Maxillofac Surg 48(4): e1-e4.
19. Obiechina AE, Arotiba JT, Fasola AO (2001) Necrotizing fasciitis of odontogenic origin in Ibadan, Nigeria. Br J Oral Maxillofac Surg 39(2): 122-126.

20. Flanagan CE, Daramola O0, Maisel RH, Adkinson C, Odland RM (2009) Surgical debridement and adjunctive hyperbaric oxygen in cervical necrotizing fasciitis. Otolaryngol Head Neck Surg 140(5): 730-734.

\begin{tabular}{|l|}
\hline \multicolumn{1}{|c|}{ Your next submission with JuniperPublishers } \\
will reach you the below assets \\
- Quality Editorial service \\
- Swift Peer Review \\
- Reprints availability \\
- E-prints Service \\
- Manuscript Podcast for convenient understanding \\
- Global attainment for your research \\
- Manuscript accessibility in different formats \\
( Pdf, E-pub, Full Text, Audio) \\
- Unceasing customer service \\
Track the below URL for one-step submission \\
http://juniperpublishers.com/online-submission.php \\
\hline
\end{tabular}

